\title{
Performance of Methanolic Extract of Artemisia herba alba as a Potential Green Inhibitor on Corrosion Behavior of Mild Steel in Hydrochloric Acid Solution
}

\author{
Siham Echihi 1,*, Rachid Hsissou ${ }^{2, * \mathbb{D}}$, Nisrine Benzbiria ${ }^{3}$, Moha Afrokh ${ }^{1}$, Maria Boudalia ${ }^{1}$, Abdelkebir \\ Bellaouchou ${ }^{1}$, Abdellah Guenbour ${ }^{1}$, Mohamed Azzi ${ }^{3}$, Mohamed Tabyaoui ${ }^{1}$ \\ 1 Laboratory of Materials, Nanotechnology and Environment, Faculty of Sciences, Mohammed V University, Av. Ibn \\ Battouta, PO Box 1014 Agdal-Rabat, Morocco \\ 2 Laboratory of Organic Chemistry, Catalysis and Environment, Department of Chemistry, Faculty of Sciences, University \\ Ibn Tofail, BP 242, 14000, Kenitra, Morocco \\ 3 Laboratory of Interface Materials and Environment, Hassan II University (UH II), B.P. 5366 Maârif, Casablanca, Morocco \\ * Correspondence: echihisiham@gmail.com (S.E.); r.hsissou@gmail.com (R.H.);
}

Scopus Author ID 57193233249

Received: 12.02.2021; Revised: 15.03.2021; Accepted: 18.03.2021; Published: 31.03.2021

\begin{abstract}
The influence of the methanolic extract of Artemisia herba alba (MEAHA) as a potential green inhibitor on the corrosion behavior of mild steel in $1 \mathrm{M} \mathrm{HCl}$ solution in the presence of different concentrations (200 to $500 \mathrm{ppm}$ ) was explored and investigated using weight loss (WL) method, potentiodynamic polarization (PDP) technique, electrochemical impedance spectroscopy (EIS) measurement, scanning electron microscope (SEM) analysis, energy dispersive spectroscopy (EDS), temperature effect, Langmuir adsorption isotherm, and kinetic thermodynamic parameters. Obtained results suggest that the increases in MEAHA concentration lead to increases in the anti-corrosive protection efficiencies, which are 91, 89, and 90\% for WL, PDP, and EIS, respectively. SEM analysis resulting after soaking in the corrosion inhibitor solution, the surface of mild steel is still relatively smooth for $24 \mathrm{~h}$. Adsorption of MEAHA obeyed Langmuir adsorption isotherm model. Also, MEAHA green inhibitor is very well adsorbed by the active centers on MS area.
\end{abstract}

Keywords: MEAHA; green inhibitor; corrosion behavior; mild steel; MEB/EDS; Langmuir adsorption.

(C) 2021 by the authors. This article is an open-access article distributed under the terms and conditions of the Creative Commons Attribution (CC BY) license (https://creativecommons.org/licenses/by/4.0/).

\section{Introduction}

Recently, several researchers have been studying the development and investigation of new methods, materials, and technologies that can delay the corrosion of steel using essential oil and extracts of Artemisia herba alba as a potential green corrosion inhibitor in aggressive acidic mediums ( $\mathrm{HCl}, \mathrm{H}_{3} \mathrm{PO}_{4}, \mathrm{H}_{2} \mathrm{SO}_{4}, \mathrm{HNO}_{3}$, etc.) [1-4]. Methanolic extract of Artemisia is a natural substance that is not toxic for humans and environmentally friendly. It could be employed as a potential green inhibitor for mild steel protection in the hydrochloric acid solution $(1 \mathrm{M} \mathrm{HCl})$ [5]. The anti-corrosive inhibition efficiencies of natural inhibitors for mild steel include chemical conversion disposal, anodic oxidation, laser disposal, corrosion inhibitory and coatings, etc. Adding the methanolic extract of Artemisia herba alba has several advantages: the excellent anti-corrosive property, the low cost, and the very simple equipment, and widely employed in many industries such as chemical, cosmetic, other, etc. [6-8]. Corrosion inhibition of the mild steel surface is protected by the physical, chemical, and/or 
physicochemical adsorption between the metallic surfaces and products investigated to form insoluble thin films by chemical adsorption prevent further corrosion of substrate [9-15]. The effective adsorption of corrosion inhibition requires the presence of multiple bonds and the heterocyclic compounds having heteroatoms such as nitrogen, sulfur, oxygen, phosphorus, etc. [16-22]. The development and investigation of new green inhibitors and the improvement of anti-corrosive protective efficiency are the primary objectives of green corrosion inhibitor research. Presently, the corrosion research of mild steel in $1 \mathrm{M} \mathrm{HCl}$ medium mainly focuses on the influence of microstructure and phase structure on their anti-corrosive performance. However, the influence of ion $\mathrm{Cl}$ and concentration on the anti-corrosive protection behavior of green corrosion inhibitor is reported in several pieces of literature [23-26]. The objective of our present study is the development and application of a methanolic extract of Artemisia herba alba as a potential green anti-corrosive inhibitor for mild steel in $1 \mathrm{M} \mathrm{HCl}$ medium. Then, the methanolic extract of Artemisia herba alba was studied and investigated for outgoing application as a potential green corrosion inhibitor for mild steel using weight loss (WL), potentiodynamic polarization (PDP), electrochemical impedance spectroscopy (EIS), scanning electron microscopy (SEM), energy-dispersive X-ray spectroscopy (EDS), temperature effect, Langmuir adsorption isotherm and kinetic thermodynamic parameters [27, 28].

\section{Materials and Methods}

\subsection{Extraction of the methanolic extract of Artemisia Herba Alba.}

In the Imilchil area in the Atlas Mountains of Morocco, Artemisia herba alba was gathered fresh during February (2016). Randomly, it is dried in the shade, protected from moisture, and kept carefully in a non-humid and ventilated area within the Laboratory of Materials, Nanotechnology, and Environment at the Faculty of Sciences, Mohammed V University in Rabat. An electric mill is used to grind the aerial part of these species until a powder was obtained. Using Soxhlet for $8 \mathrm{~h}, 30 \mathrm{~g}$ of this aerial part's powder is subjected to methanol extraction $[29,30]$. The extract was, therefore, concentrated completely in a rotary evaporator. Until its use is needed, the residue was saved in a tightly closed vial of colored glass at $4^{\circ} \mathrm{C}$.

\subsection{Material employed and corrosive solution.}

In this study, mild steel (MS) specimens was employed as a material with a chemical composition $(\mathrm{C}=0.29, \mathrm{Cr}=0.18, \mathrm{Mn}=0.62, \mathrm{P}=0.05, \mathrm{Cu}=0.27, \mathrm{~S}=0.05, \mathrm{Ni}=0.09, \mathrm{Al}=0.02$ and rest of iron). Also, the MS samples were treated and polished with emery paper (600 to 2000), rinsed with double-distilled water and degreased with propanone and ethanol at room temperature. For WL, PDP and EIS tests, the MS sample surface was $1 \mathrm{~cm}^{2} .1 \mathrm{M} \mathrm{HCl}$ solution was realized using a dilution of $37 \% \mathrm{HCl}$ with bidistilled water [31]. The concentration range of MEAHA studied was 200 to 500ppm.

\subsection{Electrochemical investigation.}

The corrosion inhibition effect of MEAHA on MS samples was performed using the potentiostat PGZ 301 (Radiometer Analytical) apparatus. Then, the electrochemical cell is composed of three electrodes. They are mild steel that operates as a working electrode. The platinium serves as a counter electrode and the saturated calomel electrode stands as a reference 
electrode, respectively [32]. The PDP parameter was $0.3 \mathrm{mV} / \mathrm{s}$ of scan rate in the range of -800 to $0 \mathrm{mV} / \mathrm{SCE}$, and the EIS parameter was $10 \mathrm{mV}$ of sine wave voltage and the frequency between 100 to $10 \mathrm{mHz}$. The effect of temperatures was realized and investigated at 303,313, 323 , and $333 \mathrm{~K}$, respectively.

\subsection{SEM and EDS analysis.}

Scanning electron microscope (SEM) and the energy dispersive spectroscopy (EDS) analysis (JEOL JSM-IT 100 type) was employed to investigate the morphology of the MS substrate area immersion in $1 \mathrm{M} \mathrm{HCl}$ uninhibited and inhibited by optimal concentration (500 ppm) of the MEAHA tested as a potential green inhibitor, with an accelerating voltage of 20 $\mathrm{kV}$ [33].

\section{Results and Discussion}

\subsection{Weight loss measurements.}

Weight loss (WL) measurements were employed to study the anti-corrosion inhibition efficiencies for $\mathrm{MS}$ in $1 \mathrm{M} \mathrm{HCl}$ solution without and with different concentrations of methanolic extract of Artemisia herba alba investigated as a potential green inhibitor. The corrosion rate $(\mathrm{W})$ and the corrosion inhibition efficiency $(\mathrm{\eta}(\%))$ were calculated according to equations 1 and 2, respectively [34]. The Wand $\eta(\%)$ are listed in Table $1[35,36]$.

$$
\begin{aligned}
& \mathrm{W}=\frac{\left(\mathrm{m}_{1}-\mathrm{m}_{2}\right)}{\mathrm{S} . \mathrm{t}} \\
& \eta(\%)=\frac{\left(\mathrm{W}^{0}-\mathrm{W}_{\mathrm{inh}}\right)}{\mathrm{W}^{0}} \times 100
\end{aligned}
$$

Where $\mathrm{m}_{1}, \mathrm{~m}_{2}, \mathrm{~W}^{0}, \mathrm{~W}_{\mathrm{inh}}, \mathrm{S}$, and $\mathrm{t}$ denote the initial weight, the final weight, the corrosion rate without inhibitor, the corrosion rate with different concentrations of methanolic extract of Artemisia herba alba, the surface of MS and the time, respectively.

Table 1. Weight loss and inhibition efficiency without and with varying concentration of MEAHA

\begin{tabular}{c|c|c|c} 
Concentrations (ppm) & $\mathbf{W}\left(\mathbf{m g ~ c m} \mathbf{~ m}^{-\mathbf{- 1}}\right)$ & $\mathbf{\eta}(\boldsymbol{\%})$ & $\boldsymbol{\theta}$ \\
\hline Blank & 0.670 & & 0.66 \\
\hline 200 & 0.226 & 66 & 0.79 \\
\hline 300 & 0.141 & 79 & 0.86 \\
\hline 400 & 0.091 & 86 & 0.91
\end{tabular}

As shown in Table 1, the weight loss decreases with increases in the methanolic extract of Artemisia herba alba concentrations, owing to that the $\eta(\%)$ increases. Then, the maximum $\eta(\%)$ value at the optimum concentration of methanolic extract of Artemisia herba alba (500 ppm) was $91 \%$. The increase of the MEAHA concentrations causes by an increase considerably in the anti-corrosive inhibition efficiencies. However, suppose the MEAHA Alba concentrations increase above an optimal value. In that case, the green inhibitor adsorbs on a mild steel surface by the electrostatic interaction.

\subsection{Potentiodynamic polarization test.}

Potentiodynamic polarization plots of mild steel in $1 \mathrm{M} \mathrm{HCl}$ medium without varying concentrations (200 to $500 \mathrm{ppm}$ ) of MEAHA as a green inhibitor are shown in Figure 1. The 
relevant electrochemical parameters are grouped in Table 2. The corrosion inhibition efficiency was calculated according to equation 3 [37-39].

$$
\eta_{\text {PDP }}(\%)=\left(\frac{i_{0}-i_{\text {inh }}}{i_{0}}\right) \times 100
$$

With io and $i_{\text {corr }}$ denote the corrosion current density in the absence and presence of varying concentrations of methanolic extract of Artemisia herba alba.

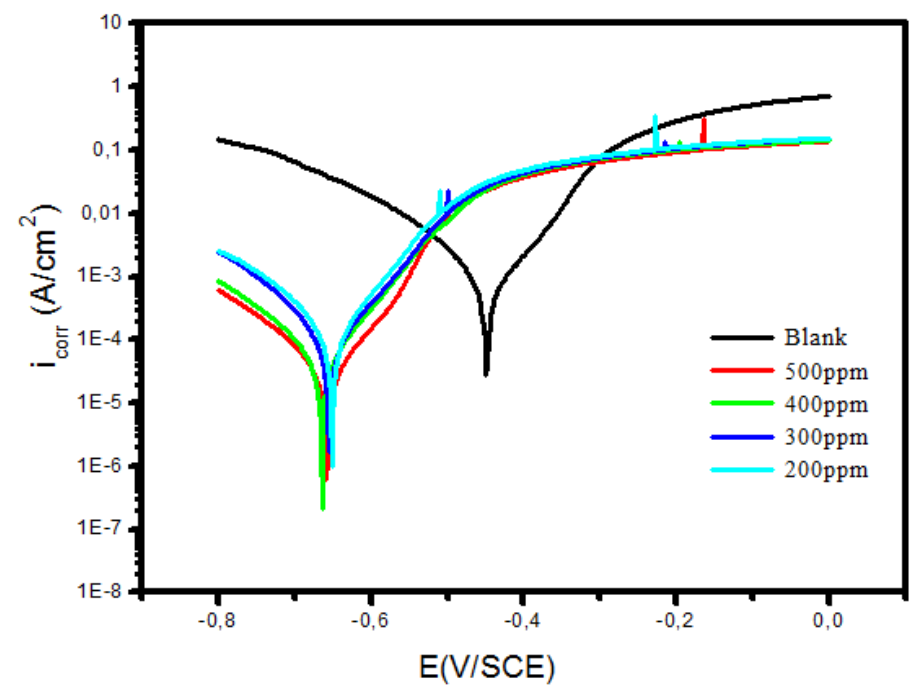

Figure 1. Polarization plots for $\mathrm{MS}$ in $1 \mathrm{M} \mathrm{HCl}$ medium without and with HEAHA.

Table 2. Varying electrochemical parameters obtained from PDP without and with different concentrations of

\begin{tabular}{|c|c|c|c|c|c|c|}
\hline \multicolumn{7}{|c|}{ MEAHA. } \\
\hline Inhibitor & $\begin{array}{c}\text { Concentration } \\
\text { ppm }\end{array}$ & $\begin{array}{c}\text {-Ecorr } \\
\left(\mathbf{m V} V_{\text {SCE }}\right)\end{array}$ & $\begin{array}{c}-\beta_{c} \\
\left(\mathbf{m V} \cdot \mathbf{d e c}^{-1}\right)\end{array}$ & $\begin{array}{c}\boldsymbol{\beta a} \\
\left.(\mathbf{m V . d e c})^{-1}\right)\end{array}$ & $\begin{array}{c}\text { icorr } \\
\left(\mu \mathbf{A . c m}^{-2}\right)\end{array}$ & $\eta_{\text {PDP }}(\%)$ \\
\hline \multirow{5}{*}{ MEAHA } & $1 \mathrm{M} \mathrm{HCl}$ & 449 & 92 & 186 & 570 & - \\
\hline & 200 & 452 & 98 & 64 & 162 & 72 \\
\hline & 300 & 656 & 111 & 71 & 117 & 79 \\
\hline & 400 & 663 & 118 & 36 & 81 & 86 \\
\hline & & 659 & 128 & 52 & 65 & 89 \\
\hline
\end{tabular}

As a result, indicated in Figure 1 and Table 2, it is confirmed that the cathodic branches show a typical Tafel behavior, while the anodic branches in the presence of the methanolic extract of Artemisia herba alba as a green inhibitor reveal that has been related to the modification in the coverage degree of the MEAHA, which is owing to the reorientation of the heteroatoms of the MEAHA Alba formed on the mild steel surface [26]. The corrosion of mild steel is inhibited in $1 \mathrm{M} \mathrm{HCl}$ medium alone using controlling both anodic dissolution and hydrogen evolution reaction, however by preventing surface blocking since both $\beta \mathrm{a}$ and $\beta \mathrm{c}$ are modified in the presence of a different concentration of MEAHA as a green inhibitor. Thus, there is a difference between the cathodic branch and the anodic branch. For a more detailed explanation, Figure 1 displays the PDP curves obtained without and in the presence of 200 to $500 \mathrm{ppm}$ of MEAHA in $1 \mathrm{M} \mathrm{HCl}$ solution [27]. Noting that the corrosion current densities of the cathodic and anodic branches in aggressive corrosion solution decreasing with an increase in the concentration of green inhibitor studied, however the corrosion potential shifts toward the more negative values, indicating in corrosion inhibition mitigation, which is owing to the methanolic extract of Artemisia herba alba green inhibitor adsorbed on the metallic surfaceactive centers in $1 \mathrm{M} \mathrm{HCl}$ solution [14]. The MEAHA in $1 \mathrm{M} \mathrm{HCl}$ solution is an cathodic-type inhibitor. 


\subsection{Electrochemical impedance spectroscopy test.}

Figure 2 displays the electrochemical impedance spectroscopy plots performed on mild steel in $1 \mathrm{M} \mathrm{HCl}$ medium in the absence and the presence of various concentrations of the methanolic extract of Artemisia Herba Alba. The different electrochemical parameters are grouped in Table 3. The reduction of corrosion inhibition of the mild steel is largely attributed to the presence of MEAHA, including the adsorption and the film formation on MS, owing to the adsorption of green inhibitor studied and the distance between the substrate surface and a corrosive solution is increased [40]. These facts could be seen through the Nyquist curves obtained from the EIS study. The protective inhibition efficiency was determined according to the following equation 4 [41]:

$$
\eta_{\text {EIS }}(\%)=\left(\frac{\mathrm{R}_{\text {inh }}-\mathrm{R}_{0}}{\mathrm{R}_{\mathrm{inh}}}\right) \times 100
$$

Where $\mathrm{R}_{0}$ and $\mathrm{R}_{\text {inh }}$ denote the polarization resistance values in the absence and the presence of MEAHA inhibitor.

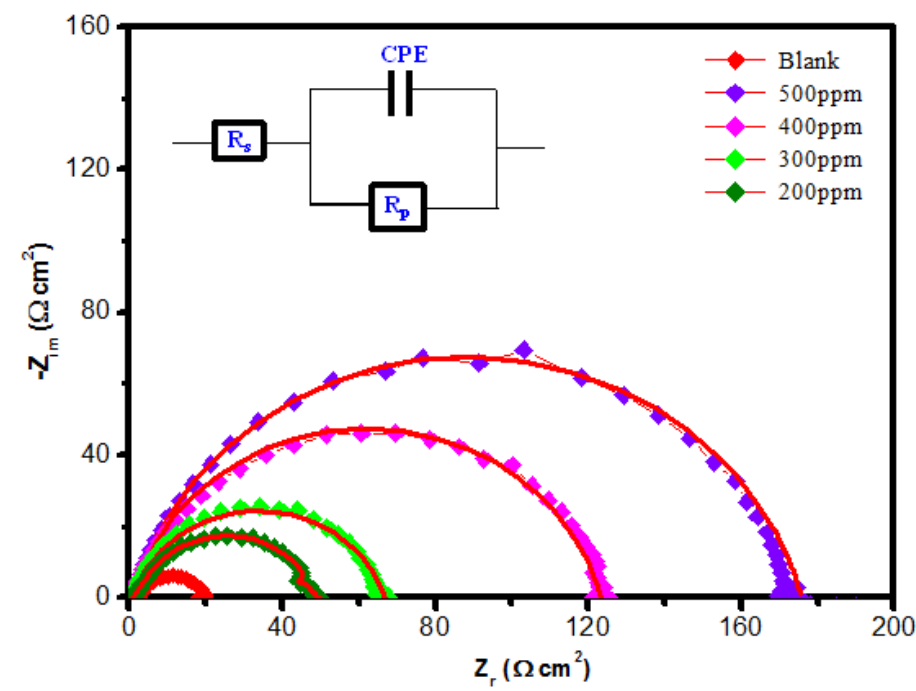

Figure 2. Nyquist curve for $\mathrm{MS}$ in $1 \mathrm{M} \mathrm{HCl}$ solution without and with varying concentrations of MEAHA. Inset: Electrochemical equivalent circuits used to fit the impedance data.

Table 3. Varying electrochemical parameters obtained from EIS without and with different concentrations of

\begin{tabular}{|c|c|c|c|c|c|c|c|}
\hline \multicolumn{8}{|c|}{ MEAHA. } \\
\hline Inhibitor & $\begin{array}{c}\mathbf{C} \\
(\mathbf{p p m})\end{array}$ & $\begin{array}{c}\mathbf{R}_{\mathrm{s}} \\
\left(\mathbf{\Omega . c m ^ { 2 }}\right)\end{array}$ & $\begin{array}{c}\mathbf{R}_{\mathrm{tc}} \\
\left(\mathbf{\Omega . c m}^{2}\right)\end{array}$ & $\begin{array}{c}\mathbf{Q} \\
\left(\mu \mathbf{F} \mathbf{S}^{n-1}\right)\end{array}$ & $\mathbf{n}_{\mathrm{dl}}$ & $\begin{array}{c}C_{\mathrm{dll}^{-2}} \\
\left.\boldsymbol{C m}^{-2}\right)\end{array}$ & $\eta_{\text {EIS }}(\%)$ \\
\hline $1 \mathrm{M} \mathrm{HCl}$ & - & 1.16 & 17 & 462 & 0.800 & 138 & - \\
\hline \multirow{4}{*}{ MEAHA } & 200 & 2.759 & 49 & 470.4 & 0.7113 & 167 & 65 \\
\hline & 300 & 2.789 & 67 & 243.7 & 0.8087 & 122 & 75 \\
\hline & 400 & 2.695 & 124 & 92.55 & 0.8398 & 31.08 & 86 \\
\hline & 500 & 3.101 & 176 & 62.04 & 0.8381 & 52.31 & 90 \\
\hline
\end{tabular}

As a result in Figure 2, alone one capacity loop appears in the frequency studies' impedance spectra, which suggests that the single charger transfer resistance is the main reason indicating in anti-corrosive in the absence and the presence of the methanolic extract of Artemisia herba alba green inhibitor. That is possibly related to the charge transfer reaction, the frequency dispersion, the metallic surface inhomogeneity, and the surface roughness [40]. As such, the higher semicircle implies that the covering film is present in the MS surface. That presence is made possible thanks to the MEAHA adsorption that works to reduce the corrosion process. Also, semicircles' diameter increases with the increase of green inhibitor concentration 
up to $500 \mathrm{ppm}$ [42]. At higher frequencies range, there is the one which could correspond to the metallic surface corrosion compounds. The other one is at lower frequencies, which may be attributed to the charge transfer process at the substrate/solution interface. An equivalent electrical circuit: Rs is solution resistance, $\mathrm{Rp}$ is polarization resistance, and CPE is a constant phase element $[43,44]$. Owing to the surface roughness, the porous layer formation and the inhibitor adsorption, there is no ideal capacitive behavior in $1 \mathrm{M} \mathrm{HCl}$ solution. Also, $\mathrm{CPE}$ is realized to replace the double layer capacity $\left(\mathrm{C}_{\mathrm{dl}}\right)$ to get the better-fitting plots with the nonideal capacitance response [45]. The maximum inhibition efficiency in $1 \mathrm{M} \mathrm{HCl}$ solution is $90 \%$. Then, the $\mathrm{R}_{\mathrm{s}}$ value increases with the increase of MEAHA concentration, resulting in that the chloride ions may reduce the solution's resistance. Also, the $\mathrm{R}_{\mathrm{ct}}$ value elevates with the increase of MEAHA concentration, which is because that the increase of concentration of chloride ions strengthens the damage of the protective layer on the metallic surface and reduces the corrosion resistance (Table 3) [46].

\subsection{Adsorption isotherm.}

The Langmuir adsorption isotherm of the corrosion inhibition on the metallic surface in $1 \mathrm{M} \mathrm{HCl}$ solution is shown in Figure 3. As a result in Figure 3, when the $\mathrm{R}^{2}$ is close to the unit, the $\mathrm{C}$ is linearly related to the $\mathrm{C} / \theta$. The Langmuir adsorption isotherm is defined as the following equations 5 and $6[47,48]$ :

$$
\frac{\mathrm{C}_{\mathrm{inh}}}{\theta}=\frac{1}{\mathrm{~K}_{\mathrm{ads}}}+\mathrm{C}_{\mathrm{inh}}
$$

$$
\Delta \mathrm{G}_{\mathrm{ads}}^{0}=(-\mathrm{RT}) \times \operatorname{Ln}\left(55.5 \mathrm{~K}_{\mathrm{ads}}\right)(6)
$$

The $\Delta \mathrm{G}_{\text {ads }}^{0}$ value in $1 \mathrm{M} \mathrm{HCl}$ medium investigated has to value close to $-20 \mathrm{~kJ} \cdot \mathrm{mol}^{-1}$, resulting in that the physisorption dominates. Not alone $\mathrm{K}_{\mathrm{ads}}$, however, also $\Delta \mathrm{G}_{\text {ads }}^{0}$ of methanolic extract of Artemisia herba alba is the largest in $1 \mathrm{M} \mathrm{HCl}$, indicating the strongest adsorption as shown in Table 4, which is in perfect agreement with their similar electrochemical result.

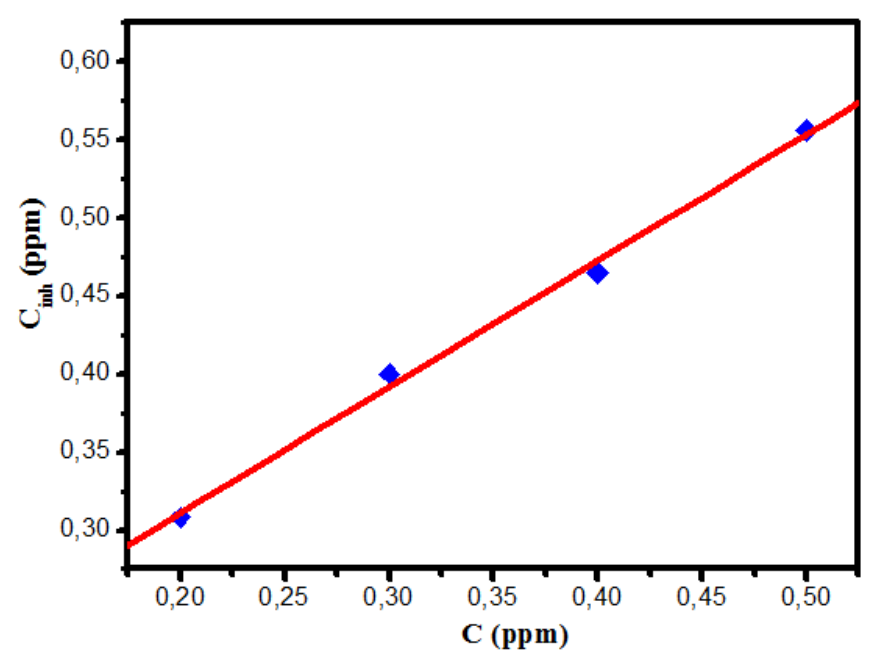

Figure 3.Langmuir adsorption isotherm curve for the MEAHAin $1 \mathrm{M} \mathrm{HCl}$ medium fitted by EIS data.

Table 4.Varyin parameters for Langmuir adsorption isotherm of MS with MEAHA.

\begin{tabular}{l|l|l|l|l} 
Inhibitor & $\mathbf{R}^{\mathbf{2}}$ & Slope & $\mathbf{K}_{\text {ads }}(\mathbf{L} / \mathbf{g})$ & $\Delta \mathrm{G}_{\text {ads }}^{\circ}\left(\mathbf{K J}_{\left.\mathbf{J} . \mathbf{m o l}^{-\mathbf{1}}\right)}\right.$ \\
\hline MEAHA & 0.99999 & 0.809 & 6.71 & -22.2
\end{tabular}




\subsection{Temperature effect and kinetic parameters.}

The temperature effect was realized to investigate the resistance of the film adsorbed on the mild steel in $1 \mathrm{M} \mathrm{HCl}$ without and with an optimal concentration of the MEAHA (500 $\mathrm{ppm}$ ) as a potential green inhibitor (we investigated the potentiodynamic polarization in the temperature range 303 to $333 \mathrm{~K}$ ) [49-51]. The PDP curves of the MS surface in $1 \mathrm{M} \mathrm{HCl}$ only and with MEAHA (500 ppm) at varying temperatures are presented in Figure 4. The different electrochemical parameters are listed in Table 5.
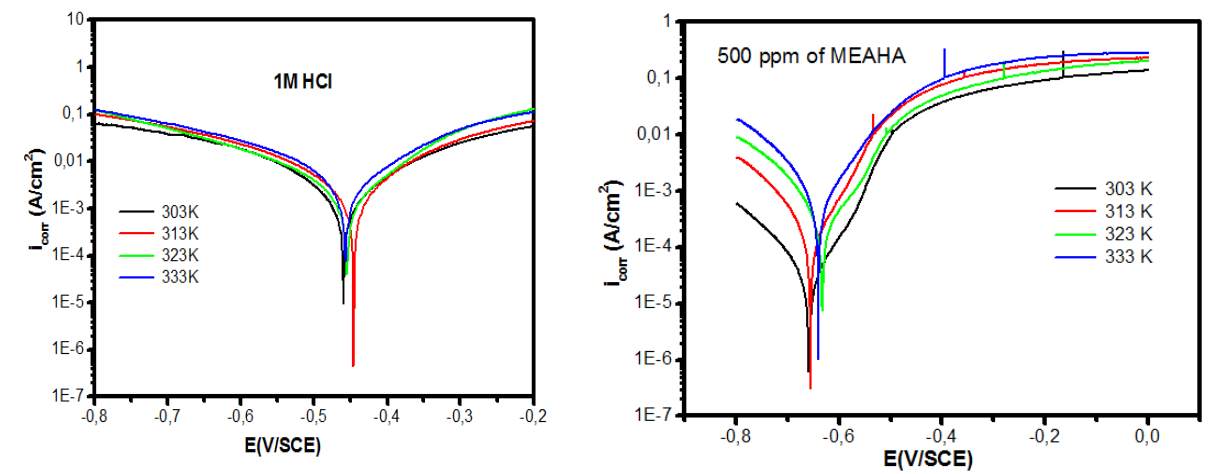

Figure 4. Temperature effect on the polarization plots of $\mathrm{MS}$ in $1 \mathrm{M} \mathrm{HCl}$ without and with $500 \mathrm{ppm}$ of MEAHA at varying temperatures.

As a result, in Figure 4 and Table 5, we remarked that the corrosion current density for MS uninhibited and inhibited increases with an increase in temperature, which is owing to the diminishing of the anti-corrosive inhibition efficiencies. Several parameters were investigated to understand the adsorption mechanism of the anti-corrosion protection between the MEAHA and MS arias, such as activation energy $\left(E_{a}\right)$, standard activation enthalpy $\Delta H_{a}^{\circ}$, and standard activation entropy $\Delta S_{a}^{\circ}$. These parameters were calculated for MS uninhibited and inhibited with optimum concentration of the MEAHA according to the Arrhenius equation and alternative formula of the Arrhenius (equations 7 and 8) [14].

$$
\begin{gathered}
\mathrm{i}_{\text {corr }}=\operatorname{Kexp}\left(\frac{-\mathrm{E}_{\mathrm{a}}}{\mathrm{RT}}\right) \\
\mathrm{i}_{\text {corr }}=\frac{\mathrm{RT}}{\mathrm{Nh}} \exp \left(\frac{\Delta \mathrm{S}_{\mathrm{a}}^{\circ}}{\mathrm{RT}}\right) \exp \left(-\frac{\Delta \mathrm{H}_{\mathrm{a}}^{\circ}}{\mathrm{RT}}\right)
\end{gathered}
$$

The $\mathrm{Ln}$ (icorr) as a function of $1000 / \mathrm{T}$ for MS in $\mathrm{HCl}$ medium alone and with MEAHA at an optimal concentration (500 ppm) was displayed in Figure 5. Then, the $\operatorname{Ln}\left(\mathrm{i}_{\text {corr }} / \mathrm{T}\right)$ as a function of 1000/T uninhibited and inhibited with MEAHA (500 ppm) was presented in Figure 6. Also, varying kinetic parameters such as $\mathrm{E}_{\mathrm{a}}, \Delta \mathrm{H}_{\mathrm{a}}^{\circ}$ and $\Delta \mathrm{S}_{\mathrm{a}}^{\circ}$ calculated are grouped in Table 5. The activation energy value in the presence of the MEAHA is more than that of the $\mathrm{HCl}$ only, which owing that the higher energy was procured with MEAHA employed as a potential green inhibitor [52]. Also, the standard activation enthalpy positive value of methanolic extract of Artemisia herba alba suggests that the MS dissolution process is an endothermic reaction. 


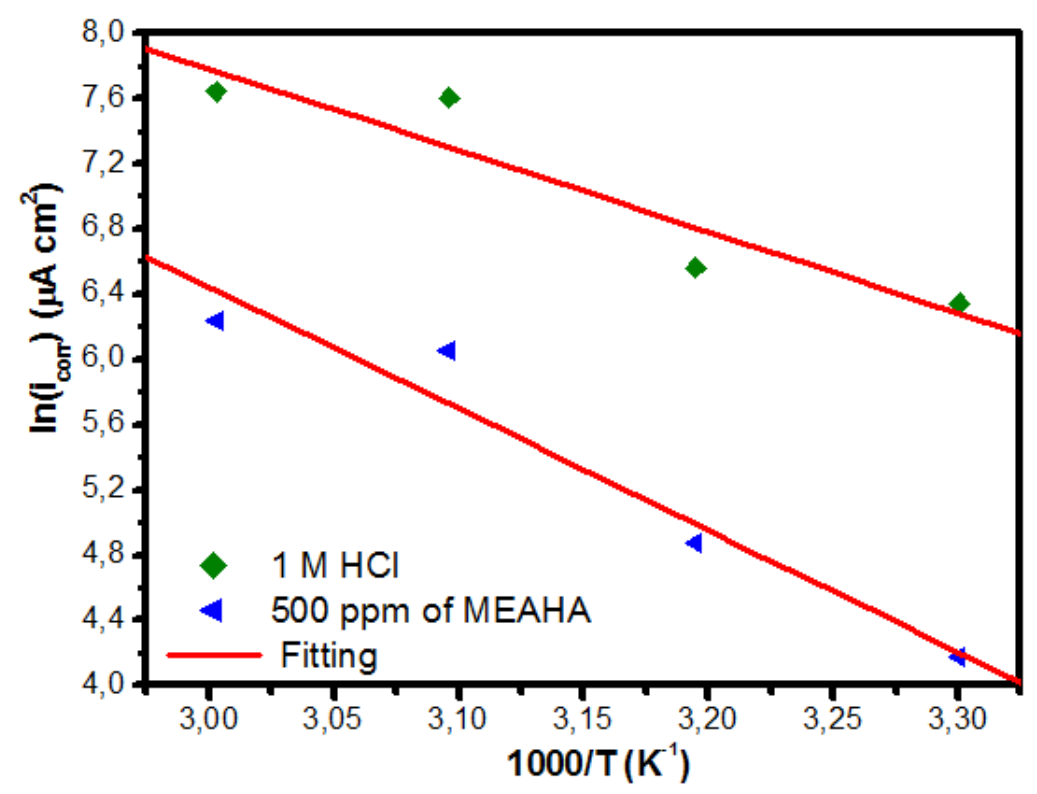

Figure 5. $\mathrm{Ln}\left(\mathrm{i}_{\text {corr }}\right)$ as function of $1000 / \mathrm{T}$ for $\mathrm{MS}$ in $\mathrm{HCl}$ without and with $500 \mathrm{ppm}$ of MEAHA.

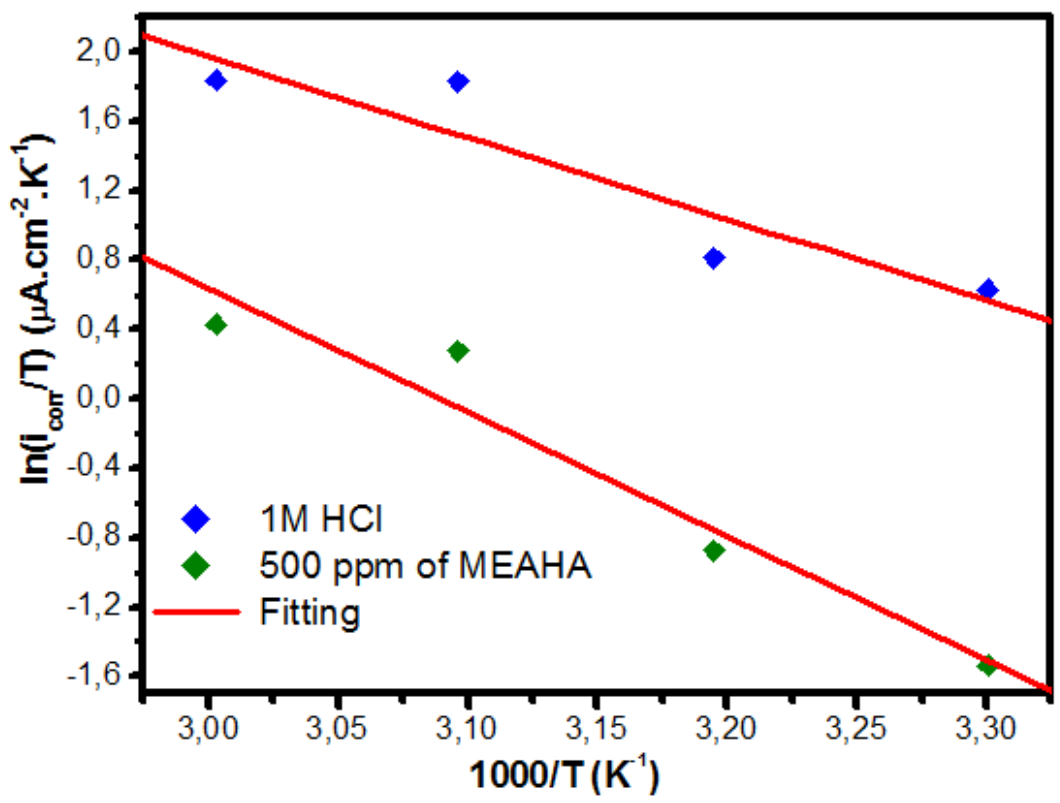

Figure 6. $\mathrm{Ln}\left(\mathrm{i}_{\text {corr }} / \mathrm{T}\right)$ as a function of $1000 / \mathrm{T}$ for $\mathrm{MS}$ in $\mathrm{HCl}$ without and with $500 \mathrm{ppm}$ of MEAHA.

Table 5. PDP and kinetic parameters of MS in $1 \mathrm{M} \mathrm{HCl}$ solution in the absence and présence of $500 \mathrm{ppm}$ of

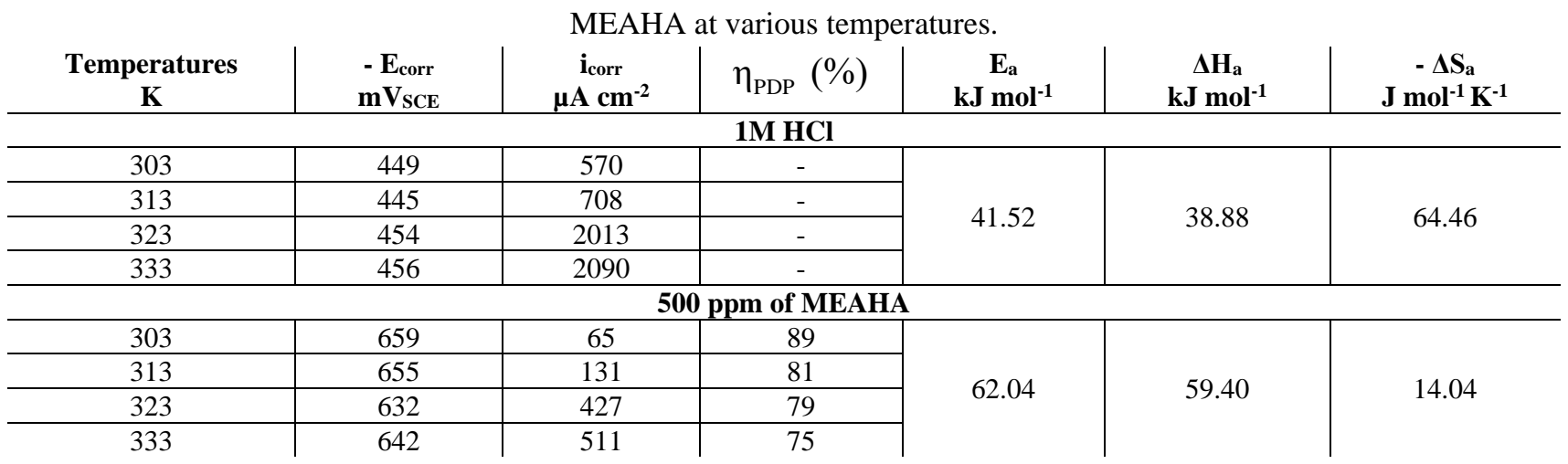




\subsection{SEM/EDS characterization.}

Using scanning electron microscopy (SEM), it has become possible to document the micrographs (Figure 7) of the mild steel strips' surfaces. The objective is to examine the transformations that occur during the corrosion process when 500ppm of AHAME is present and absent after $24 \mathrm{~h}$ of immersion. So as to get enough information about the properties investigated in the sample of the surface of the steel both in the absence and presence of inhibitor in $1 \mathrm{M} \mathrm{HCl}$, EDX analyses were done. Due to the absence of the extracts (Figure 7), the steel composition becomes hard and gets damaged after being immersed in $1 \mathrm{M}$ hydrochloric acid solution because of the force of the rapid corrosion. As a matter of fact, there is a presence of a layer of corrosion product able to absorb fluids [53]. On the contrary, when we add to the aggressive environment 500ppm of plant extract, this leads to a remarkable decrease in mild steel's corrosive attack (Figure 7). As a result, the constitution of corrosion products gets hindered. This blockage leads to a process of changing to an inferior state of the mild steel. Indeed, as the SEM images demonstrate, there is a sort of improvement at the surface coverage level, and the protective film on the steel surface starts to take shape. The prime reason behind this is associated with the downward change in the interaction between the steel of the surface and the aggressive medium. It is evident from Figure 7 that the EDX spectrum contained in aggressive solution $(1 \mathrm{M} \mathrm{HCl})$ introduces the characteristic and most extreme possible values of particular elements included in the surface of the sample's chemical properties. As such, when the plant extract exists, both the feature peak of nitrogen and enhancement in the intensity level of the peaks of oxygen and carbon become visibly apparent. These are present in the tested inhibitor's chemical constitution [1].
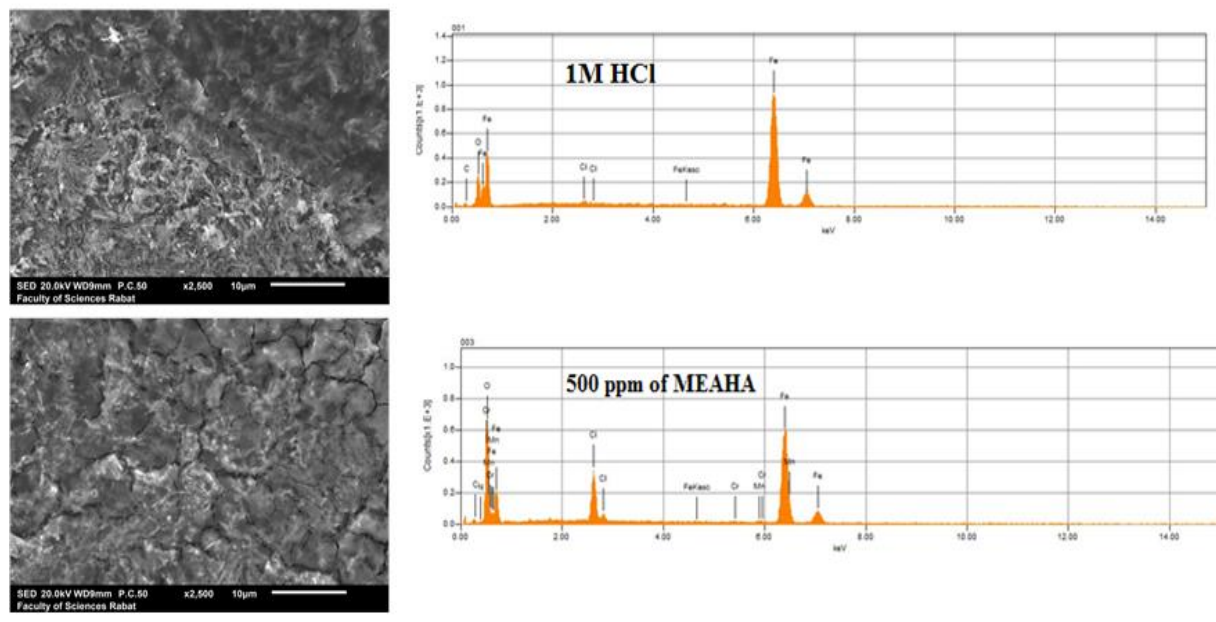

Figure 7. SEM/EDS images of the MS without and with 500 ppm of MEAHA.

\section{Conclusions}

The corrosion resistance of the corrosion inhibition of the methanolic extract of Artemisia herba alba used as a green inhibitor in $1 \mathrm{M} \mathrm{HCl}$ solution was investigated, and the following conclusions were obtained: As the concentration of MEAHA increases, the Rs of the solutions and the Rct of corrosion reaction was increased, and the optimal corrosion inhibition efficiencies are 91, 89, and 90\% for WL, PDP and EIS, respectively; The resistance of corrosion inhibition is due to corrosion inhibitors' coverage to reduce mild steel's exposure surface; The small insoluble molecules react with corrosion products owing to the hydrophobic effect of corrosion inhibitors; SEM analysis indicates that the green inhibitor investigation 
leads to smooth film formation on the metal surface in $1 \mathrm{M} \mathrm{HCl}$ solution; These studies are very interesting and motivate researchers to improve the methanolic extract of Artemisia herba alba as a green inhibitor, as a corrosion inhibitor, and as an anti-corrosive coating.

\title{
Funding
}

This research received no external funding.

\section{Acknowledgments}

\begin{abstract}
Many thanks to Prof. Mohamed Tabyaoui at Faculty of Sciences, Mohamed 5 University, Morocco. Also, many thanks to Doctor Rachid HSISSOU, who collaborated to the success of this paper. All evaluators of this work gave enough time to review it with their excellent remarks and questions to give it some value.
\end{abstract}

\section{Conflicts of Interest}

The authors declare no conflict of interest.

\section{References}

1. Boudaliaa, M.; Fernández-Domeneb, R.M.; Tabyaouia, M.; Bellaouchoua, A.; Guenboura, A.; GarcíaAntónb, J. Green approach to corrosion inhibition of stainless steel in phosphoric acid of Artemesia herba albamedium using plant extract. J. Mater. Res. Technol. 2019, 8, 5763-5773, https://doi.org/10.1016/j.jmrt.2019.09.045.

2. Ouachikh, O.; Bouyanzer, A.; Bouklah, M.; Desjobert, J.M.; Costa, J.; Hammouti, B.; Majidi, L. Application of essential oil of Artemisia herba alba as green corrosion inhibitor for steel in $0.5 \mathrm{M} \mathrm{H}_{2} \mathrm{SO}_{4}$. Surface Review and Letters2009, 16, 49-54, https://doi.org/10.1142/S0218625X09012287.

3. Boumhara, K.; Harhar, H.; Tabyaoui, M.; Bellaouchou, A.; Guenbour, A.; Zarrouk, A. Corrosion Inhibition of Mild Steel in $0.5 \mathrm{M} \mathrm{H}_{2} \mathrm{SO}_{4}$ Solution by Artemisia herba-alba Oil. Journal of Bio- and Tribo-Corrosion 2019, 5, https://doi.org/10.1007/s40735-018-0202-8.

4. Bouyanzer, A.; Bouklah, M.; Chetouani, A.; Majidi, L.; Hammouti, B.; Aouniti, A. Valorization of essential oil and extracts of Artemisia herba alba in the inhibition of corrosion and antibacterial and other effectsReview. Arabian Journal of Chemical and Environmental Research2017, 4, 31-45.

5. Benabdellah, M.; Benkaddour, M.; Hammouti, B.; Bendahhou, M.; Aouniti, A. Inhibition of steel corrosion in $2 \mathrm{M}$ H3PO4 by artemisia oil. Applied Surface Science 2006,252, 62126217,https://doi.org/10.1016/j.apsusc.2005.08.030.

6. Boudalia, M.; Guenbour, A.; Bellaouchou, A.; Fernandez-Domene, R.M.; Garcia-Anton, J. Corrosion behaviour of a highly alloyed austenitic alloy UB6 in contaminated phosphoric acid. Int. J. Corros.2013, 2013, 1-9, https://doi.org/10.1155/2013/363826.

7. Benmenine, A.; Mechraoui, O.; Ben ali, M.; Tabchauch, M.; Rida Ouahrani, M.; Gherraf, N.; Lamine Sekirifa, M.; Baameur, L. Essential Oil Extract of Artemisia herba-alba as Green Inhibitor against the Corrosion of X52 Steel in 20\% Sulfuric Acid Medium. World Journal of Environmental Biosciences2014, 7, 56-58.

8. Bammou, L.; Mihit, M.; Salghi, R.; Bouyanzer, A.; Al-Deyab, S.S.; Bazzi, L.; Hammouti, B. Inhibition Effect of Natural Artemisia Oils Towards Tinplate Corrosion in $\mathrm{HCl}$ solution: Chemical Characterization and Electrochemical Study. Int. J. Electrochem. Sci.2011, 6, 1454-1467.

9. Batah, A.; Anejjar, A.; Bammou, L.; Belkhaouda, M.; Salghi, R. Effect of apricot almond oil as green inhibitor for steel corrosion in hydrochloric media. Port. Electrochim. Acta2020, 38, 201-214, https://doi.org/10.4152/pea.202004201.

10. Hsissou, R.; Benhiba, F.; Khudhair, M.; Berradi, M.; Mahsoune, A.; Oudda, H.; El Harfi, A.; Obot, I.B.; Zarrouk, A. Investigation and comparative study of the quantum molecular descriptors derived from the theoretical modeling and Monte Carlo simulation of two new macromolecular polyepoxide architectures TGEEBA and HGEMDA. Journal of King Saud University-Science 2020, 32, 667676,https://doi.org/10.1016/j.jksus.2018.10.008.

11. Dagdag, O.; Hsissou, R.; El Harfi, A.; Berisha, A.; Safi, Z.; Verma, C.; Ebenso, E.E.; Ebn Touhami, M.; El Gouri, M. Fabrication of polymer based epoxy resin as effective anti-corrosive coating for steel: Computational modeling reinforced experimental studies. Surfaces and Interfaces 2020, 18, https://doi.org/10.1016/j.surfin.2020.100454. 
12. Dagdag, O.; Hsissou, R.; El Harfi, A.; Safi, Z.; Berisha, A.; Verma, C.; Ebenso, E.E.; Quraishi, M.A.; Wazzan, N.; Jodeh, S.; El Gouri, M. Epoxy resins and their zinc composites as novel anti-corrosive materials for copper in 3\% sodium chloride solution: Experimental and computational studies. J. Mol. Liq. 2020, 315, https://doi.org/10.1016/j.molliq.2020.113757.

13. Hssissou, R.; Benzidia, B.; Hajjaji, N.; Elharfi, A. Elaboration, Electrochemical Investigation and morphological Study of the Coating Behavior of a new Polymeric Polyepoxide Architecture: Crosslinked and Hybrid Decaglycidyl of Phosphorus Penta methylene Dianiline on E24 Carbon Steel in 3.5\% NaCl. Portugaliae Electrochimica Acta 2019, 37, 179-191,http://dx.doi.org/10.4152/pea.201903179.

14. Ouachikh, O.; Bouyanzer, A.; Bouklah, M. Desjobert, J.M.; Costa, J.; Hammouti, B.; Majidi, L. Application of essential oil of Artemisia herba alba as green corrosion inhibitor for steel in $0.5 \mathrm{~m}_{2} \mathrm{SO}_{4}$. Surface Review and Letters2009, 16, 49-54,https://doi.org/10.1142/S0218625X09012287.

15. Hsissou, R.; Benzidia, B.; Hajjaji, N.; Elharfi, A. Elaboration and electrochemical studies of the coating behavior of a new nanofunctional epoxy polymer on E24 steel in 3.5\% NaCl. Portugaliae Electrochimica Acta 2018, 36, 259-270,http://dx.doi.org/10.4152/pea.201804259.

16. Dagdag, O.; Safi, Z.; Hsissou, R.; Erramli, H.; El Bouchti, M.; Wazzan, N.; Guo, L.; Verma, C.; Ebenso, E.E.; El Harfi, A. Epoxy pre-polymers as new and effective materials for corrosion inhibition of carbon steel in acidic medium: Computational and experimental studies. Sci. Rep. 2019, 9, https://doi.org/10.1038/s41598-019-48284-0.

17. Benhiba, F.; Hsissou, R.; Benzekri, Z.; Belghiti, M.E.; Lamhamdi, A.; Bellaouchou, A.; Guenbour, A.; Boukhris, S.; Oudda, H.; Warad, I.; Zarrouk, A. Nitro substituent effect on the electronic behavior and inhibitory performance of two quinoxaline derivatives in relation to the corrosion of mild steel in $1 \mathrm{M} \mathrm{HCl}$. J. Mol. Liq. 2020, 312, https://doi.org/10.1016/j.molliq.2020.113367.

18. Hsissou, R.; El Harfi, A. Application of Pentaglycidyl ether Penta-ethoxy Phosphorus Composites Polymers Formulated by Two Additives, Trisodium Phosphate (TSP) and Natural Phosphate (NP) and their Combination in the Behavior of the Coating on E24 Carbon Steel in $\mathrm{NaCl} 3.5 \%$. Anal. Bioanal. Electrochem. 2018, 10, 728-738.

19. Benhiba, F.; Serrar, H.; Hsissou, R.; Guenbour, A.; Bellaouchou, A.; Tabyaoui, M.; Boukhris, S.; Oudda, H.; Warad, I.; Zarrouk, A. Tetrahydropyrimido-Triazepine derivatives as anti-corrosion additives for acid corrosion: Chemical, electrochemical, surface and theoretical studies. Chem. Phys. Lett. 2020, 743, https://doi.org/10.1016/j.cplett.2020.137181.

20. Hsissou, R.; Benhiba, F.; Abbout, S.; Dagdag, O.; Benkhaya, S.; Berisha, A.; Erramli, H.; Elharfi, A. Trifunctional epoxy polymer as corrosion inhibition material for carbon steel in $1.0 \mathrm{M} \mathrm{HCl}$ : MD simulations, DFT and complexation computations. Inorg. Chem. Commun. 2020, 115, https://doi.org/10.1016/j.inoche.2020.107858.

21. Saxena, A.; Thakur, K.K.; Bhardwaj, N. Electrochemical studies and surface examination of low carbon steel by applying the extract of Musa acuminata. Surfaces and Interfaces2020, 18, https://doi.org/10.1016/j.surfin.2020.100436.

22. Hsissou, R.; Abbout, S.; Seghiri, R.; Rehioui, M.; Berisha, A.; Erramli, H.; Assouag, M.; Elharfi, A. Evaluation of corrosion inhibition performance of phosphorus polymer for carbon steel in [1M] $\mathrm{HCl}$ : Computational studies (DFT, MC and MD simulations). Journal of Materials Research and Technology2020, 9, 2691-2703,https://doi.org/10.1016/j.jmrt.2020.01.002.

23. Lahhit, N.; Bouyanzer, A.; Desjobert, J. M.; Hammouti, B.; Salghi, R.; Costa, J.; Jama, C.; Bentiss, F.; Majidi, L. Fennel (Foeniculum vulgare) essential oil as green corrosion inhibitor of carbon steel in hydrochloric acid solution. Portugaliae Electrochimica Acta2011, 29, 127138,https://doi.org/10.4152/pea.201102127.

24. Boumhara, K.; Bentiss, F.; Tabyaoui, M.; Costa, J.; Desjobert, J.M.; Bellaouchou, A.; Guenbour, A.; Hammouti, B.; Al-Deyab, S.S. Use of Artemisia Mesatlantica Essential Oil as Green Corrosion Inhibitor for Mild Steel in $1 \mathrm{M}$ Hydrochloric Acid Solution. Int. J. Electrochem. Sci.2014, 9, 1187-1206.

25. Subhadra, G.; Saraswati G.; Parasuraman J.; Singh, J.K.; Adirajan, E. A comprehensive study on crude methanolic extract of Artemisia pallens (Asteraceae) and its active component as effective corrosion inhibitors of mild steel in acid solution. Corrosion Science2012, 60, 193204,http://dx.doi.org/10.1016/j.corsci.2012.03.036.

26. Boumhara, K.; Tabyaoui, M.; Jama, C.; Bentiss, F. Artemisia Mesatlantica essential oil as green inhibitor for carbon steel corrosion in $1 \mathrm{M} \mathrm{HCl}$ solution: Electrochemical and XPS investigations. Journal of Industrial and Engineering Chemistry 2015, 29, 146-155,http://dx.doi.org/10.1016/j.jiec.2015.03.028.

27. Boumhara, K.; Tabyaoui, M.; Jama, C.; Bentiss, F. Artemisia Mesatlantica essential oil as green inhibitor for carbon steel corrosion in $1 \mathrm{M} \mathrm{HCl}$ solution: Electrochemical and XPS investigations. Journal of Industrial and Engineering Chemistry2015, 29, 146-155,http://dx.doi.org/10.1016/j.jiec.2015.03.028.

28. Bourazmi, H.; Tabyaoui, M.; El Hattabi, L.; Aoufir, Y.E.; Taleb, M. Methanolic Extract of Salvia Officinalis plant as a green inhibitor for the corrosion of carbon steel in $1 \mathrm{M} \mathrm{HCl}$. J. Mater. Environ. Sci.2018, 9, 928938. 
29. Afrokh, M.; Echihi, S.; Tabyaoui, M.; S, T.; Hormatallah, A.; Hatimi, A.; Hicham, H.; Faydy, M.; Zarrouk, A.; Electrochemistry, B. The valorization of the hammada scoparia extract as an eco-friendly corrosion inhibitor for carbon steel corrosion in $1 \mathrm{M} \mathrm{HCl}$. Anal Bioanal Electrochem. 2019, 11, 1482-1499.

30. Chatoui, K.; Echihi, S.; Harhar, H.; Zarrouk, A.; Tabyaoui, M. An investigation of carbon steel corrosion inhibition in $1 \mathrm{M} \mathrm{HCl}$ by Lepidium sativum oil as green inhibitor. J Mater Environ Sci.2018, 9, 1212-1223.

31. Ezzanad, A.; Benkaddour, R.; Echihi, S.; Harhar, H.; Tabyaoui, M.; Zarrouk, A. Anticorrosive activity of euphorbia officunarum extract for carbon steel in $1 \mathrm{M} \mathrm{HCl}$. Journal of Chemical Technology and Metallurgy, 2021, 56, 194-204.

32. Belghiti, M.E.; Bouazama, S.; Echihi, S.; Mahsoune, A.; Elmelouky, A.; Dafali, A.; Emran, K.M.; Hammouti, B.; Tabyaoui, M. Understanding the adsorption of newly Benzylidene-aniline derivatives as a corrosion inhibitor for carbon steel in hydrochloric acid solution: Experimental, DFT and molecular dynamic simulation studies. Arabian Journal of Chemistry 2020, 13, 14991519,https://doi.org/10.1016/j.arabjc.2017.12.003.

33. Echihi, S.; Tabyaoui, M.; Qafsaoui, W. Inhibitive effect of 1,3,4-thiadiazole-2,5-dithiol on copper corrosion in chloride media. Int J Corros Scale Inhib.2019, 8, 329-355, https://doi.org/10.17675/2305-6894-2019-82-14.

34. Echihi, S.; Benzbiria, N.; Belghiti, M.E.; El Fal, M.; Boudalia, M.; Essassi, E.M.; Guenbour, A.; Bellaouchou, A.; Tabyaoui, M.; Azzi, M. Corrosion inhibition of copper by pyrazole pyrimidine derivative in synthetic seawater: Experimental and theoretical studies. Materials Today: Proceedings 2021, 37, 39583966,https://doi.org/10.1016/j.matpr.2020.09.264.

35. Hsissou, R.; Benzidia, B.; Rehioui, M.; Berradi, M.; Berisha, A.; Assouag, M.; Hajjaji, N.; Elharfi, A. Anticorrosive property of hexafunctional epoxy polymer HGTMDAE for E24 carbon steel corrosion in $1.0 \mathrm{M} \mathrm{HCl}$ : gravimetric, electrochemical, surface morphology and molecular dynamic simulations. Polymer Bulletin 2020, 77, 3577-3601, https://doi.org/10.1007/s00289-019-02934-5.

36. Hsissou, R.; Abbout, S.; Safi, Z.; Benhiba, F.; Wazzan, N.; Guo, L.; Nouneh, K.; Briche, S.; Erramli, H.; Ebn Touhami, M.; Assouag, M.; Elharfi, A. Synthesis and anti-corrosive properties of epoxy polymer for $\mathrm{CS}$ in $[1 \mathrm{M}] \mathrm{HCl}$ solution: Electrochemical, AFM, DFT and MD simulations. Construction and Building Materials 2021, 270,https://doi.org/10.1016/j.conbuildmat.2020.121454.

37. Benzbiria, N.; Echihi, S.; Belghiti, M.E.; Thoume, A.; Elmakssoudi, A.; Zarrouk, A.; Zertoubi, M.; Azzi, M. Novel synthetized benzodiazepine as efficient corrosion inhibitor for copper in $3.5 \% \mathrm{NaCl}$ solution. Materials Today: Proceedings 2021, 37, 3932-3939,https://doi.org/10.1016/j.matpr.2020.09.030.

38. Dagdag, O.; Hsissou, R.; Berisha, A.; Erramli, H.; Hamed, O.; Jodeh, S.; El Harfi, A. Polymeric-Based Epoxy Cured with a Polyaminoamide as an Anti-corrosive Coating for Aluminum 2024-T3 Surface: Experimental Studies Supported by Computational Modeling. Journal of Bio- and Tribo-Corrosion 2019, 5 , https://doi.org/10.1007/s40735-019-0251-7.

39. Hsissou, R.; Bekhta, A.; Elharfi, A.; Benzidia, B.; Hajjaji, N. Theoretical and electrochemical studies of the coating behavior of a new epoxy polymer: hexaglycidyl ethylene of methylene dianiline (HGEMDA) on E24 steel in $3.5 \%$ NaCl. Portugaliae Electrochimica Acta 2018, 36, 101117,http://dx.doi.org/10.4152/pea.201802101.

40. Tabatabaei majd, M.; Bahlakeh, G.; Dehghani, A.; Ramezanzadeh, B.; Ramezanzadeh, M. Combined molecular simulation, DFT computation and electrochemical studies of the mild steel corrosion protection against $\mathrm{NaCl}$ solution using aqueous Eucalyptus leaves extract molecules linked with zinc ions. Journal of Molecular Liquids 2019, 294,https://doi.org/10.1016/j.molliq.2019.111550.

41. Hsissou, R.; Benhiba, F.; Echihi, S.; Benkhaya, S.; Hilali, M.; Berisha, A.; Briche, S.; Zarrouk, A.; Nouneh, K.; Elharfi, A. New epoxy composite polymers as a potential anti-corrosive coatings for carbon steel in $3.5 \%$ $\mathrm{NaCl}$ solution: Experimental and computational approaches. Chemical Data Collections 2021, 31, https://doi.org/10.1016/j.cdc.2020.100619.

42. Salarvand, Z.; Amirnasr, M.; Talebian, M.; Raeissi, K.; Meghdadi, S. Enhanced corrosion resistance of mild steel in $1 \mathrm{M} \mathrm{HCl}$ solution by trace amount of 2-phenyl-benzothiazole derivatives: Experimental, quantum chemical calculations and molecular dynamics (MD) simulation studies. Corrosion Science 2017, 114, 133145,https://doi.org/10.1016/j.corsci.2016.11.002.

43. Hsissou, R.; Benassaoui, H.; Benhiba, F.; Hajjaji, N.; El Harfi, A. Application of a new trifunctional epoxy prepolymer, triglycidyl ethylene ether of bisphenol A, in the coating of E24 steel in 3.5\% NaCl. Journal of Chemical Technology and Metallurgy 2017, 52, 431-438.

44. Yan, T.; Zhang, S.; Feng, L.; Qiang, Y.; Lu, L.; Fu, D.; Wen, Y.; Chen, J.; Li, W.; Tan, B. Investigation of imidazole derivatives as corrosion inhibitors of copper in sulfuric acid: Combination of experimental and theoretical researches. J. Taiwan Inst. Chem. Eng.2020, 106, 118-129, https://doi.org/10.1016/j.jtice.2019.10.014.

45. Hsissou, R.; Benhiba, F.; Zarrouk, A.; Oudda, H.; Elharfi, A. Electrochemical studies, Monte Carlo simulation and DFT of a new composite - pentaglycidyl ether pentaphenoxy of phosphorus - crosslinked and hybrid in its coating behavior on E24 carbon steel in 3.5\% NaCl. Port. Electrochimica Acta 2021, 39, 119,https://doi.org/10.4152/pea.202101001. 
46. He, T.; Emori, W.; Zhang, R.H.; Okafor, P.C.; Yang, M.; Cheng, C.R. Detailed characterization of Phellodendron chinense Schneid and its application in the corrosion inhibition of carbon steel in acidic media. Bioelectrochemistry2019, 130, https://doi.org/10.1016/j.bioelechem.2019.107332.

47. Rbaa, M.; Benhiba, F.; Hssisou, R.; Lakhrissi, Y.; Lakhrissi, B.; Touhami, M.E.; Warad, I.; Zarrouk, A. Green synthesis of novel carbohydrate polymer chitosan oligosaccharide grafted on d-glucose derivative as bio-based corrosion inhibitor. J. Mol. Liq. 2021,322,https://doi.org/10.1016/j.molliq.2020.114549.

48. Hsissou, R.; Dagdag, O.; Abbout, S.; Benhiba, F.; Berradi, M.; El Bouchti, M.; Berisha, A.; Hajjaji, N.; Elharfi, A. Novel derivative epoxy resin TGETET as a corrosion inhibition of E24 carbon steel in $1.0 \mathrm{M} \mathrm{HCl}$ solution. Experimental and computational (DFT and MD simulations) methods. J. Mol. Liq. 2019, 284, 182192,https://doi.org/10.1016/j.molliq.2019.03.180.

49. Singh, P.; Chauhan, D.S.; Chauhan, S.S.; Singh, G.; Quraishi, M.A. Chemically modified expired Dapsone drug as environmentally benign corrosion inhibitor for mild steel in sulphuric acid useful for industrial pickling process. J. Mol. Liq.2019, 286, https://doi.org/10.1016/j.molliq.2019.110903.

50. Thirumangalam Karunanithi, B.; Chellappa, J. Adsorption and inhibition properties of Tephrosia Purpurea as corrosion inhibitor for mild steel in sulphuric acid solution. J. Dispers. Sci. Technol.2019, 40, 1441-1450, https://doi.org/10.1080/01932691.2018.1516150.

51. Hsissou, R.; Abbout, S.; Berisha, A.; Berradi, M.; Assouag, M.; Hajjaji, N.; Elharfi, A. Experimental, DFT and molecular dynamics simulation on the inhibition performance of the DGDCBA epoxy polymer against the corrosion of the E24 carbon steel in $1.0 \mathrm{M} \mathrm{HCl}$ solution. J. Mol. Struct. 2019, 1182, 340351,https://doi.org/10.1016/j.molstruc.2018.12.030.

52. Manelle, R.; Ferkous, H.; Zerroug, M.; Djellali, S.; Aymen Chaouch, M.; Hattabi, B.; Majdoub, H.; Boutahala, M. Methanolic Extract of Artemisia herba alba as Eco-Friendly Inhibitor of Carbon Steel Corrosion in 1M HCl Media. Recent Advances in Environmental Science from the Euro-Mediterranean and Surrounding Regions, Advances in Science, Technology \& Innovation 2018, https://doi.org/10.1007/978-3319-70548-4_403.

53. Belghiti, M.; Ouadi, Y.; Echihi, S.; Elmelouky, A.; Outada, H.; Karzazi, Y.; Bakasse, M.; Jama, C.; Bentiss, F.; Dafali, A.J.S. Anti-corrosive properties of two 3.5-dissubstitud-4-amino-1.2.4-triazole derivatives on copper in hydrochloric acid environment: Ac impedance, thermodynamic and computational investigations. Surfaces and Interfaces, 2020, 21, https://doi.org/101016/j.surfin.2020.100692. 